\title{
DETECTING REGIONAL VARIATION USING META-ANALYSIS AND LARGE-SCALE SAMPLING: LATITUDINAL PATTERNS IN RECRUITMENT
}

\author{
T. P. Hughes, ${ }^{1,6}$ A. H. Baird, ${ }^{2}$ E. A. Dinsdale, ${ }^{2}$ V. J. Harriott,${ }^{3}$ N. A. Moltschaniwskyj $, 2,4$ \\ M. S. Pratchett, ${ }^{2}$ J. E. TANner, ${ }^{2,5}$ And B. L. Willis ${ }^{2}$ \\ ${ }^{1}$ Centre for Coral Reef Biodiversity, Department of Marine Biology, James Cook University, \\ Townsville, Queensland 4811, Australia \\ ${ }^{2}$ Department of Marine Biology, James Cook University, Townsville, Queensland 4811, Australia \\ ${ }^{3}$ CRC Reef Research Center, James Cook University, Townsville, Queensland 4811, Australia \\ ${ }^{4}$ School of Aquaculture, University of Tasmania, Launceston, P.O. Box 1214, Tasmania 7250, Australia \\ ${ }^{5}$ SARDI Aquatic Sciences, P.O. Box 120 Henley Beach, South Australia 5022 Australia
}

\begin{abstract}
Regional-scale variation of recruitment by marine organisms may reflect geographic patterns in adult stock sizes or fecundities, large-scale hydrodynamic features that influence the transport of larvae (e.g., currents, upwelling), and patterns of early mortality. In turn, recruitment may play a vital role in determining patterns of adult abundance and community structure, from local to biogeographic scales. We examined spatial variation in recruitment by corals at a regional scale, along $3300 \mathrm{~km}$ of the tropical and subtropical coast of eastern Australia $\left(10^{\circ}-31^{\circ} \mathrm{S}\right)$. We used two complementary approaches: (1) a metaanalysis of 21 different studies undertaken over a 16-yr period, each of which was generally conducted at a single reef, and (2) a large-scale sampling effort in which recruitment was measured in two years on 33 reefs arrayed along the length of the Great Barrier Reef (GBR). Our goal is to compare the emergent large-scale picture derived from many small-scale studies with patterns revealed by shorter-term regional sampling.

The two approaches show very similar large-scale patterns. Recruitment by spawning corals (mainly acroporids) was highest in the central GBR and declined steadily with increasing latitude by up to more than 20-fold. A smaller decline occurred on the northern GBR between Australian and Papua New Guinea. Recruitment by brooding corals (mostly pocilloporids) was greatest in the northern GBR and also declined to the south. The latitudinal decline in brooders was three- to fivefold, i.e., not as great as for spawners. Consequently, the proportion of brooded recruits increased to the south, and they generally exceeded spawners on the southern GBR and on isolated subtropical reefs at higher latitudes. Our meta-analysis shows that fully half of the variation in the ratio of spawners to brooders is attributable to one of 11 variables that we extracted from the published studies: the month when the recruitment panels were deployed. This result suggests that the intensity and timing of spawning have a crucial impact on large-scale patterns of recruitment. Elsewhere, we tested this hypothesis in the field, and confirmed that regional variation in recruitment by spawning acroporid corals was driven by spatial and temporal variation in the extent of mass spawning. Together, large-scale sampling and meta-analyses provide a powerful, combined approach for investigating large-scale patterns and the mechanisms underlying them.
\end{abstract}

Key words: coral reefs; Great Barrier Reef; larvae; meta-analysis; population dynamics; recruitment; spatial scale.

\section{INTRODUCTION}

The ability to compare and synthesize across studies is crucial for revealing general patterns and for scaling up from small-scale investigations to unveil regional or global phenomena. Meta-analysis (defined as the quantitative analysis of data that originated from several independent studies) provides major advantages over more traditional narrative syntheses and reviews (e.g., Hedges and Olkin 1985, Gurevitch and Hedges

Manuscript received 10 January 2000; revised 2 February 2001; accepted 18 February 2001; final version received 9 April 2001.

${ }^{6}$ E-mail: terry.hughes@jcu.edu.au
1993). Following the lead from the social sciences (e.g., Glass et al. 1981) and medicine (e.g., Sachs et al. 1987), applications of meta-analysis to ecological data are becoming increasingly common (see recent overviews by Arnqvist and Wooster 1990, Osenberg et al. 1999). Regardless of whether the primary studies under investigation are descriptive or experimental, the underlying approach and objectives are the same: to quantify emergent patterns by applying statistical procedures, and to test for effects of ecological factors or methodology by analyzing subgroups of the overall data.

A growing awareness of scale dependency, advances in technology (e.g., satellite imagery, supercomputers) 
and increasing concern for environmental issues (e.g., habitat fragmentation, global warming) are encouraging ecologists to focus more on larger scale phenomena (e.g., Dayton and Tegner 1984, Edwards et al. 1994, Rosenzweig 1995). However, most ecological experiments and measurements are undertaken at relatively small scales of space and time, using relatively small sampling units (Schneider 1994). Ecologists often implicitly extrapolate their results across scales, typically inferring large-scale patterns from smaller scale investigations that are logistically easier to conduct. Unfortunately, these extrapolations are invalid because numerous processes (e.g., dispersal, evolution) prevail at larger scales which cannot be explored locally in space or time (see, e.g., commentaries by Wiens 1989, Rosenzweig 1995, Thrush et al. 1997). Schneider et al. (1997) suggested several solutions: undertaking largerscale experiments (e.g., Carpenter 1990), combining or replacing small-scale experiments with large-scale surveys (e.g., Eberhardt and Thomas 1991), and iterative cycling between observation, small-scale experiments on components of a larger system, and refinement of theories on how the larger system works (e.g., Rastetter et al. 1992, Wiens et al. 1993). As yet, there is no clear consensus on how best to relate patterns and processes across multiple scales.

Meta-analysis is likely to be a useful tool for detecting large-scale patterns that extend beyond the resolution or capability of conventional experimental and descriptive studies. Thus, the limited scale of focus of most ecological investigations does not preclude the detection of large-scale phenomena if results can be integrated across many studies. A classic example is the long-term dynamics of the birds of Great Britain, revealed by censuses conducted since the 1930s by thousands of members of the British Trust for Ornithology (O'Connor 1985, Taylor 1987). Similarly, biogeographers can ascertain even global-scale spatial patterns based on many localized censuses or surveys, each conducted at one or a few locations, often for different purposes and by many different individuals (e.g., Stehli and Wells 1969). In some cases, it may be feasible to examine large-scale processes or patterns in a single intensive study (e.g., Hughes et al. 1999, 2000). Whether the results emerging from a meta-analysis and a large-scale study would actually be similar is an interesting question. We are unaware of any such comparison in the ecological literature.

In this paper, we set out to compare a meta-analysis of small-scale investigations with a single large-scale study. Comparing published studies would have been easy if they had all been done and reported in the same way. However, for reasons of logistics or personal choice, each one varied, often in ways that almost certainly affected the results. Our task therefore is to identify extraneous sources of variation in the data (e.g., due to methodology), account for them with statistical models, and explore the remaining variance that is at- tributable to the variables of interest. The large-scale pattern we investigated is the density and taxonomic composition of coral recruits along a $3300 \mathrm{~km}$ tropicalsubtropical latitudinal gradient. Recruitment has a major influence on the size and composition of adult populations at all spatial scales (e.g., Gaines and Roughgarden 1985, Hughes 1990, Karlson and Levitan 1990, Caley et al. 1996, Connell et al. 1997, Hughes and Tanner 2000). Biogeographic patterns in the composition of coral assemblages (e.g., Stehli and Wells 1969) and their latitudinal limits (e.g., Crossland 1988) are likely to be strongly influenced by patterns of dispersal and recruitment. We focussed on the Great Barrier Reef and on isolated reefs to its south, where there have been 21 published reports on early recruitment by corals (on 18 separate reefs). In addition to these, we conducted a large-scale investigation of coral recruitment on 33 reefs from $10^{\circ} \mathrm{S}$ to $23^{\circ} \mathrm{S}$, along the length of the Great Barrier Reef (Hughes et al. 1999, 2000). For convenience, we refer here to these two data sets as the small- and large-scale studies, respectively.

Harriott and coworkers were the first to compare several small-scale studies to examine latitudinal patterns in the density and composition of coral recruits along the east coast of Australia (Harriott and Simpson 1996). Based on data from seven studies conducted between $16^{\circ} \mathrm{S}$ and $31^{\circ} \mathrm{S}$ (see Table 2 in Harriott and Simpson 1996), she concluded that "there is an apparent decline in the rate of recruitment of broadcasting (spawning) coral species with increasing latitude, with brooding corals being the dominant recruits at highlatitude sites" (quote from Banks and Harriott 1996). Similarly, Dunstan and Johnson (1998) stated that "the emerging picture (from the literature) is a transition from dominance of recruitment on settlement plates by (spawning) acroporids in central and northern regions of the GBR to dominance by (brooding) pocilloporids at the southern extremities of the GBR and on subtropical reefs to the south." However, neither of these conclusions was based on a formal meta-analysis of the literature. These patterns, if they occur, raise important issues concerning the mechanisms involved, and their ecological, biogeographical, and evolutionary consequences. Similar large-scale gradients in recruitment of benthic organisms occur on coastlines elsewhere. For example, changes in the abundance and population structure of echinoids along the west coast of North America (Ebert and Russell 1988), and of barnacles, mussels, and starfish on the east and west of New Zealand (Menge et al. 1999) are due in part to patterns of upwelling and the delivery of larvae. Recent modeling studies by Connolly and Roughgarden (1998, 1999) indicate the potential effects of regional-scale variation in recruitment on latitudinal patterns of adult abundances and community structure.

\section{STUdy System}

The Great Barrier Reef (GBR) is a continuous chain of nearly 3000 discrete reefs that stretches in a south- 
easterly direction from $10^{\circ} \mathrm{S}$ to $23^{\circ} \mathrm{S}$, along the coast of Queensland, Australia. Most of the reefs are 35-150 $\mathrm{km}$ offshore, depending in part on the width of the continental shelf. Isolated reefs and coral assemblages also occur south of the GBR, as far as Lord Howe Island $\left(31^{\circ} \mathrm{S}\right)$, the southernmost coral reef in the world. The species richness of reef-building corals falls by $\sim 25 \%$ between the middle and southern end of the GBR (to 245 species; Veron 1993). Eighty-seven of these extend $1100 \mathrm{~km}$ further south to Lord Howe Island (Veron and Done 1979, Harriott et al. 1995; T. P. Hughes, unpublished data). Patterns of water flow on the GBR are complex, largely because of the many gyres and eddies created by nearly 3000 reefs, and the effects of tides and variable winds. The main large-scale current flows westward towards Australia from the Coral Sea at $14^{\circ}-$ $18^{\circ} \mathrm{S}$ before bifurcating into a long-shore flow to the north and south (the Coral Sea Coastal Current and the East Australian Current, respectively; see Wolanski 1994).

Corals can be classified into two reproductive groups, brooders and spawners. Brooders release sperm, but not their eggs, which are fertilized internally to form relatively large planulae. After their release, brooded planulae have a short precompetency period (when they are not yet capable of settling) ranging from minutes to $2 \mathrm{~d}$, depending on the species (Harrison and Wallace 1990). However, planulae may remain competent for weeks if they are deprived of a suitable settlement surface (under laboratory conditions, see, e.g., Richmond 1987). The release of planulae in brooders usually follows a lunar cycle, for up to $12 \mathrm{mo} / \mathrm{yr} \mathrm{de}-$ pending on species and location (see review by Tanner 1996). The most abundant brooders on the GBR are species of Pocilloporidae (Pocillopora, Stylophora, Seriatopora), members of the Acropora subgenus Isopora, and some species of Poritidae (Harrison and Wallace 1990).

In contrast to brooders, broadcast spawners release both eggs and sperm, and fertilization is external. Most species of spawners on the GBR release their gametes in a multispecies spawning event which occurs over a period of a few days, in one or two months during the early austral summer (see Harrison et al. 1984, Babcock et al. 1986). Consequently, recruitment by most spawners is much more seasonal than brooders, with a major peak of settlement following closely after spawning (e.g., Wallace and Bull 1981, Wallace 1985a, Dunstan and Johnson 1998). The precompetency period of spawners is typically 3-7 d, more than twice as long as brooders. However, like brooders, broadcastspawned larvae can remain viable for weeks (e.g., Wilson and Harrison 1998). Over $85 \%$ of coral species on the GBR are spawners. Levels of gene-flow in corals along the GBR range from modest to low (particularly for brooders; Ayre and Hughes 2000), with minimal genetic exchange occurring between the GBR and Lord
Howe Island (D. J. Ayre and T. P. Hughes, unpublished data).

In this paper we conducted a meta-analysis of the existing literature to (1) quantify large-scale (latitudinal) patterns in recruitment by corals along the east coast of Australia, (2) measure regional changes in the proportion of recruit taxa, specifically brooders vs. spawners, and (3) compare patterns that emerge using the meta-analysis of small-scale investigations to those revealed by a single large-scale study. Our analyses points to the valuable role of meta-analysis in synthesizing results from many studies, but also highlights some limitations compared to large-scale investigations that are explicitly designed to examine regional phenomena.

\section{Methods}

The small- and large-scale studies share a basic characteristic: they all involved the deployment of replicate artificial substrata (recruitment panels), which were subsequently retrieved and censused. To avoid bias in our selection of cases for the meta-analysis, we included any publications from the study region (east Australia) that examined recruitment by corals onto artificial panels attached to hard substratum. There are 21 such primary studies, published from 1985 to 1999. The universal metric reported in these studies (and in the large-scale study) is the density of coral recruits per panel. In most cases, recruits were also classified into taxonomic categories, which allows us to examine spatial variation in both their total abundance and composition. We first plotted regressions of recruitment vs. latitude, to compare the two data sets. Then we conducted a detailed meta-analysis of the small-scale studies to further explore sources of variation in recruitment (e.g., due to methodological differences).

\section{Meta-analysis of small-scale studies}

Our task was to account for variation among previously published studies due to differences in methodology and latitude, using multiple regression models. We examined four dependent variables separately in the meta-analysis: total recruits per panel (all coral taxa combined), number of spawners, number of brooders, and the proportion of spawners to brooders. Analyses were done on both the mean number of recruits per panel, and the standardized number per $286 \mathrm{~cm}^{2}$ (the surface area of all panels in the large-scale study). The results were very similar, so we report here only on the latter. We recorded the following 11 independent variables for each small-scale study: the size and composition of panels; the method of deployment; the month, year, and duration of deployment; whether the deployment period included the month when mass spawning occurred; depth and habitat; distance offshore; and latitude. Many of these variables are correlated (see Results). We chose the following variables 
because they are very likely to have affected the amount of recruitment:

1) Panel size: Large panels should have a greater number of recruits, but they may have a lower overall density (due to "edge effects" which occur when new recruits are clustered close to the edge, presumably in response to gradients of light and water flow).

2) Panel composition: The chemical composition of recruitment panels and their rugosity or texture may affect patterns of settlement and early mortality (e.g., Harriott and Fisk 1987). The small-scale studies used six types of panels that were made of ceramic, fired clay, cement, PVC, and flat slices of dead corals.

3) Method of deployment: The published studies used three methodologies for the deployment of settlement surfaces (individual deployment of panels; panels bolted to racks side by side; panels attached to racks in vertical pairs, forming a "sandwich").

4) Duration: In any recruitment study, the longer panels are submerged the greater the opportunity for receiving multiple cohorts of larvae. However, losses of recruits due to post-settlement mortality will also be greater the longer panels are exposed. We recorded the duration of each study in weeks.

5) Month, year, and the timing of spawning: Temporal patterns of recruitment often reflect variation in the availability of competent larvae, e.g., in response to seasonal breeding cycles, or changes in hydrodynamic conditions (e.g., Babcock 1988, Milicich 1994, Hughes et al. 2000). We recorded the year and the month of initiation (when the panels were deployed) for each study. Whether or not the deployment included the month when mass spawning occurred (for that year and location) was recorded as a discrete variable, herafter called "spawning."

6) Latitude, distance from shore, habitat, depth: The latitude and distance from shore were recorded for each of the 21 small-scale studies. We categorized the habitat of each study into three types (lagoon, reef crest, reef slope). Finally, we recorded depth as a continuous variable in meters.

We used generalized additive regression models (GAM, see Hastie and Tibishirani 1990) to determine the best combination of these 11 factors that explained variation in total recruitment and recruitment by spawners and brooders separately. We first examined the correlations among the independent variables and the proportion of the variation in recruitment that was explained by each one on its own. Subsequently, we used a forward-backwards stepwise method to select the best subset and best sequence of predictors among the independent variables. At each step, we added to the model the next variable with the highest $F$ value and lowest $P$ value (provided $P<0.05$ ). After the addition of each new variable, all existing variables in the model were rechecked to ensure that they still contributed appreciably to the fit, and variables with $P<$ 0.05 were deleted. This process continued iteratively until no other variable remained which added significantly to the model. We constructed alternative models if at any stage it was unclear which variable to add or delete from the model (e.g., because of similar $F$ and $P$ values), and the completed models were compared using an analysis of deviance ( $F$ test). To examine variation in the proportion of spawners and brooders, we followed a similar procedure, except a binomial distribution (rather than a normal one) was used, and alternative models were compared using the $\chi^{2}$ distribution. Five of the independent variables were continuous (size of panel, duration of deployment, depth, latitude, and distance from the shore), while four others were categorical (composition of panels, method of deployment, whether or not the deployment overlapped with the annual mass spawning, and habitat). The remaining two independent variables of the 11 we examined, the month and year of deployment, were entered as both continuous and categorical variables, and the one with the best fit was retained. Continuous variables were entered into the model as linear variables with one degree of freedom, or as nonlinear variables using spline functions with four degrees of freedom (if the GAM indicated that the nonlinear component was significant with $P<0.05)$. One degree of freedom fits a straight line whereas $n$ degrees joins all points. Four produces "modest" smoothing (Hastie and Tibshirani 1990).

\section{Independence of data}

The definition of an independent result is important, especially for selecting multiple observations arising from a single primary study. Data collected by the same person, on the same reef, and repeatedly over time, are unlikely to be statistically independent. However, identifying which data are spatially or temporally independent from the published literature is usually impossible, or at best very subjective and a potential source of bias (e.g., Downing et al. 1999, Englund et al. 1999). Operationally, meta-analysis of published results precludes rigorous testing for spatial and temporal autocorrelations, since the original raw data are usually unavailable. Because our aim is to explore the published data as much as possible, we used multiple results from each publication wherever we could, i.e., whenever different sets of panels were deployed as part of a single study at different sites, depths, or times. This approach to meta-analysis is not unusual as a descriptive tool, e.g., Goldberg et al. (1999) examined the relationship between competition and productivity in plants using a database of 296 cases from only 14 primary studies. Similarly, our meta-analysis is based on up to 253 cases from the 21 published studies.

\section{The large-scale study}

The large-scale study examined variation in recruitment by corals at multiple scales, from meters to the length of the Great Barrier Reef (from $10^{\circ} \mathrm{S}$ to $23^{\circ} \mathrm{S}$; 


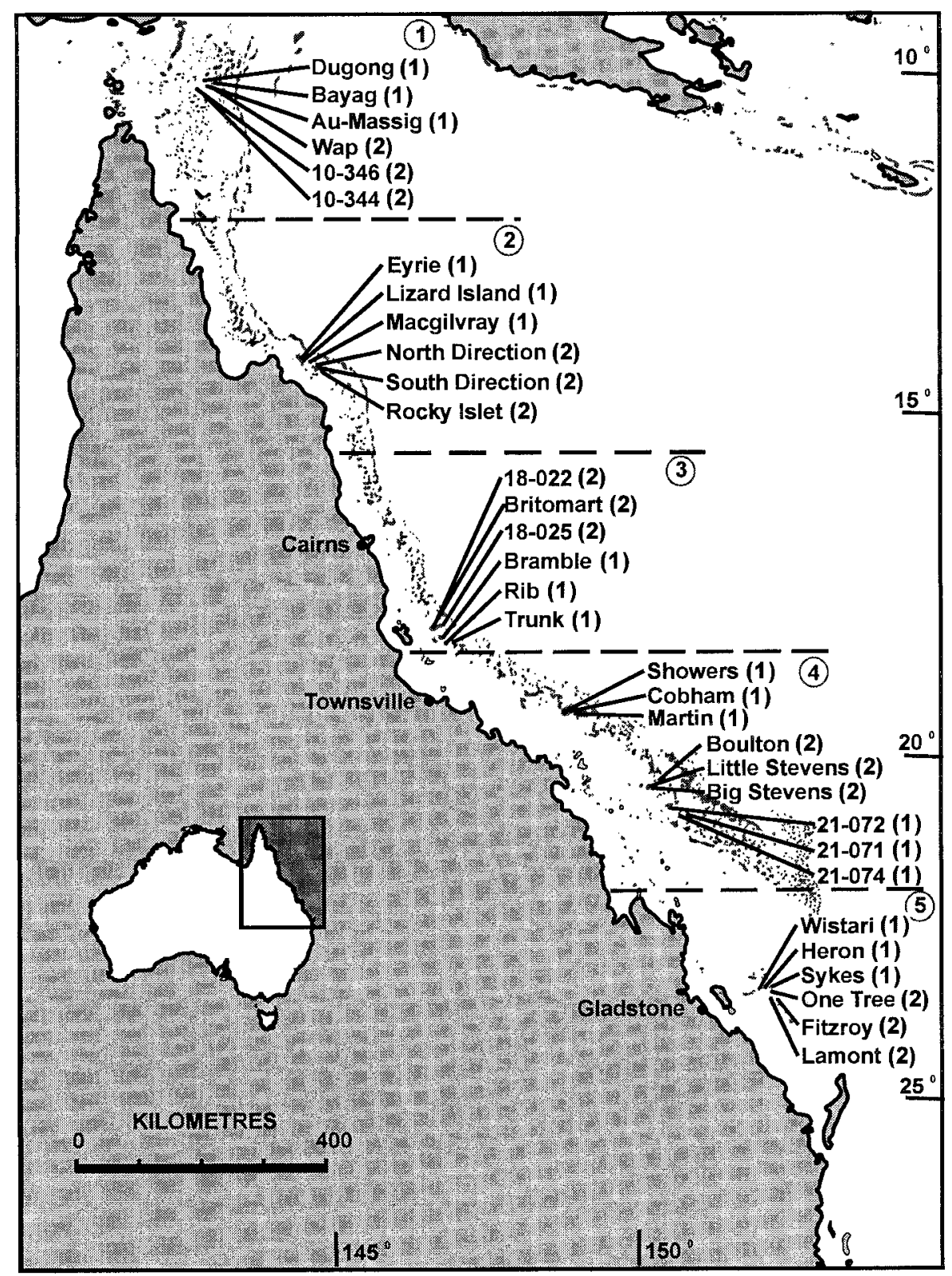

FIG. 1. Map of the Great Barrier Reef (GBR), indicating the location of reefs where recruitment of corals has been measured by the large-scale study. Note the hierarchical design, with 18 reefs in five sectors sampled during 1995-1996 (1), and a further 15 reefs during 1996-1997 (2). Sectors of the GBR are each 250-500 km apart, numbered 1-5 from north to south. The Coral Sea extends eastward, offshore from the GBR.

Fig. 1). We used a hierarchical sampling design which allowed us to partition variation (using nested ANOVAs) among four spatial scales: i.e., among five adjacent sectors from north to south along the GBR, among three to six neighboring reefs nested within each sector, among four replicate sites on each reef, and among 10 recruitment panels deployed at each site (see Hughes et al. [1999, 2000] for these analyses). Deployments were done in two consecutive years, 1995/ 6 and 1996/7 (year one and two, respectively). In year one, we targeted 18 reefs. In year two, panels were placed on 15 additional reefs. Thus, 40 panels were placed on each of the 33 reefs. Note that the panels were deployed on different reefs in separate years since our objective was to measure the effects of spatial scale rather than the predictability of recruitment at any particular site or reef (which would take many years to establish). To facilitate comparison with the small-scale studies, we report here on reef-scale patterns using the mean amount of recruitment (averaged for the 40 panels) on each reef plotted as a data point against latitude.

In contrast to the small-scale studies, the method- 
TABLE 1. Attributes of the 21 small-scale studies used in the meta-analysis (see Fig. 1 for the locations) and of the largescale study.

\begin{tabular}{|c|c|c|c|c|c|c|c|c|c|}
\hline No. & Study & $\begin{array}{l}\text { No. } \\
\text { years }\end{array}$ & $\begin{array}{l}\text { Month } \\
\text { initiated }\end{array}$ & $\begin{array}{l}\text { Deployment } \\
\text { duration (d) }\end{array}$ & $\begin{array}{l}\text { Latitude } \\
\quad\left({ }^{\circ} \mathrm{S}\right)\end{array}$ & $\begin{array}{l}\text { No. } \\
\text { reefs }\end{array}$ & $\begin{array}{l}\text { Depth } \\
(\mathrm{m})\end{array}$ & $\begin{array}{l}\text { Panel } \\
\text { material }\end{array}$ & $\begin{array}{l}\text { Panel size } \\
\quad\left(\mathrm{cm}^{2}\right)\end{array}$ \\
\hline 1 & $\begin{array}{l}\text { Baird and Hughes } \\
\text { (1997) }\end{array}$ & 1 & Jan & 56 & 14.41 & 1 & 1 & clay & 484 \\
\hline 2 & Harriott (1985) & 1 & Nov & 56 & 14.41 & 1 & 1,9 & coral & 100 \\
\hline 3 & Maida et al (1995b) & 1 & Oct & 266 & $14.41,18.40$ & 2 & 4,5 & ceramic & 675 \\
\hline 4 & $\begin{array}{l}\text { Fisk and Harriott } \\
\text { (1990) }\end{array}$ & 2 & Oct, Mar & 182 & $15.50-16.45$ & 3 & 4 & ceramic & 900 \\
\hline 5 & $\begin{array}{l}\text { Harriott and Fisk } \\
\quad(1987)\end{array}$ & 1 & Oct & 140 & 16.39 & 1 & 4 & various & $150-800$ \\
\hline 6 & $\begin{array}{l}\text { Harriott and Fisk } \\
\text { (1988) }\end{array}$ & 2 & Apr & 182 & $16.32-16.45$ & 3 & 4 & coral & 400 \\
\hline 7 & $\begin{array}{l}\text { Fisk and Harriott } \\
\text { (1994) }\end{array}$ & 1 & Nov & 147 & 16.41 & 1 & 3 & ceramic & 900 \\
\hline 8 & $\begin{array}{l}\text { Sammarco and } \\
\text { Carleton (1981) }\end{array}$ & 1 & Nov & 119 & 18.26 & 1 & 10 & coral & 600 \\
\hline 9 & Sammarco (1991) & 1 & Jan, Jul & 182,365 & $18.16-18.49$ & 3 & 3,15 & coral & $150-158$ \\
\hline 10 & $\begin{array}{l}\text { Sammarco and An- } \\
\text { drews (1988) }\end{array}$ & 1 & $\begin{array}{l}\text { Oct to } \\
\text { Mar }\end{array}$ & 210 & 18.38 & 1 & 18 & coral & 600 \\
\hline 11 & Maida et al (1995a) & 1 & Oct & 266 & 18.40 & 1 & 4 & pvc & 150 \\
\hline 12 & $\begin{array}{l}\text { Wallace \& Bull } \\
\quad(1981)\end{array}$ & 1 & Jul, Oct & 112,224 & 18.55 & 1 & $0-12$ & coral & 200 \\
\hline 13 & Wallace (1985a) & 3 & $\begin{array}{l}\text { Feb, Jun, } \\
\text { Oct }\end{array}$ & 119 & 18.55 & 1 & $0-15$ & coral & 200 \\
\hline 14 & Wallace $(1985 b)$ & 1 & Oct & 119 & 18.55 & 1 & $0-15$ & coral & 200 \\
\hline 15 & Babcock (1988) & 1 & $\begin{array}{l}\text { Dec, } \\
\text { Sept }\end{array}$ & 45 & 19.00 & 1 & 8 & ceramic & 576 \\
\hline 16 & Mundy (2000) & 1 & Jan & 112 & 23.26 & 1 & 9 & clay & $572 / 286$ \\
\hline 17 & Bothwell (1981) & 1 & $\begin{array}{l}\text { Mar, Jul, } \\
\text { Nov }\end{array}$ & 122 & 23.27 & 1 & 2 & cement & 79 \\
\hline 18 & $\begin{array}{l}\text { Dunstan and John- } \\
\text { son (1998) }\end{array}$ & 4 & Sept & 135,365 & 23.27 & 1 & 1 & ceramic & 400 \\
\hline 19 & $\begin{array}{l}\text { Banks and Harriott } \\
\text { (1996) }\end{array}$ & 2 & Jul, Nov & $56-175$ & 26.38 & 3 & 10,19 & ceramic & 900 \\
\hline 20 & $\begin{array}{l}\text { Harriott \& Banks } \\
(1995)\end{array}$ & 3 & Oct, Mar & 182 & 30.18 & 1 & 8,6 & ceramic & 900 \\
\hline \multirow[t]{2}{*}{21} & Harriott (1992) & 2 & $\begin{array}{l}\text { Nov, } \\
\quad \text { Mar }\end{array}$ & $56-238$ & 31.33 & 1 & 6,13 & ceramic & 900 \\
\hline & Large-scale study & 2 & $\begin{array}{l}\text { Nov, } \\
\text { Dec }\end{array}$ & $55-57$ & $10.28-23.38$ & 33 & 1 & clay & 286 \\
\hline
\end{tabular}

ology of the large-scale study was standardized as much as possible so that nearly all of the 11 independent variables described above were controlled for (the major exception being latitude). In each year, the panels were deployed synchronously at all sites on all reefs, $10 \mathrm{~d}( \pm 1)$ before the predicted annual mass spawning of corals, and retrieved 8 wk later. This uniform duration allowed enough time for large numbers of corals to settle, and for recruits to grow to a sufficient size (usually 1-2 $\mathrm{mm}$ ) to allow limited taxonomic resolution (generally at the family level). The habitat and depth was the same on all reefs: shallow reef crests, $\sim 1 \mathrm{~m}$ below datum. The panels were identical, unglazed clay tiles $(11 \times 11 \times 1 \mathrm{~cm})$ attached individually to the substratum by a bolt that held them $2-3 \mathrm{~cm}$ above the reef surface. A total of 1135 panels (87\%) were relocated using GPS at the 132 sites on the 33 reefs. The retrieved panels were bleached and recruits on all surfaces were counted using a dissecting microscope. Juvenile corals were identified to family (or genus where possible), and classified as spawners or brooders.

\section{Results}

\section{Comparison of data sets}

The scope of the large- and small-scale studies was quite similar. The former is based on a total of 58471 recruits on 1135 panels that were deployed on 33 reefs. The 21 published studies have a combined sample size of 47682 recruits on 538 panels from 18 different reefs (Table 1). In the large-scale data set, $83 \%$ of the recruits were spawners and $17 \%$ were brooders. In the smallscale studies, 33370 recruits $(70 \%$ of the total) were classified into different taxonomic groupings. Of these, $61 \%$ were spawners and $39 \%$ were brooders. The higher proportion of brooders in the small-scale studies reflects differences in methodology compared to the large-scale data set, and the greater southerly range of the individual studies.

As expected, there were huge differences among the small-scale studies in the 11 independent variables that we examined. For example, the censused surface area of panels was generally constant within studies, but 
varied 11-fold among them (from 79 to $900 \mathrm{~cm}^{2}$ ). Similarly, the duration of each study varied eightfold, from 6.5 to $52 \mathrm{wk}$. In comparison, the large-scale study used relatively small panels $\left(121 \mathrm{~cm}^{2}\right)$ and had a short, uniform duration of $8 \mathrm{wk}$. The small-scale studies were conducted in 14 of the 16 separate years between 1979 and 1994 (inclusive), with initial deployments in ten different months (none were in May or August, during the Austral winter). Ten of the 21 primary studies had deployment periods that did not include the peak summer mass spawning of corals. In contrast, the largescale study sampled only $2 \mathrm{yr}$, and the deployment was highly synchronized to precede the predicted mass spawning by 9-11 d. The depth range of the smallscale studies ranged from zero (intertidal) to $19 \mathrm{~m}$, compared to a uniform $1 \mathrm{~m}$ depth for the entire largescale data set. The small-scale studies were located at muddy inshore sites, on mid- and outer-shelf reefs, and on oceanic islands up to $580 \mathrm{~km}$ offshore. In contrast, the large-scale study was restricted to midshelf reefs, roughly halfway between the Australian mainland and the edge of the continental shelf (see Fig. 1).

The spatial array of study locations differed substantially between the large-scale and small-scale studies. Reefs in the large-scale data set were distributed in five to six sectors from north to south, more or less uniformly along the length of the GBR (Fig. 1). Not surprisingly, the regional spread of reefs comprising the small-scale data set was more haphazard (Fig. 2) since the individual studies were never designed to be a single sampling exercise. No reefs were sampled in the top $30 \%$ of the GBR to the north of Lizard Island $\left(14^{\circ} 40^{\prime} \mathrm{S}\right)$, while over two-thirds of the studies were conducted very close $(<100 \mathrm{~km})$ to Cairns or Townsville in the central portion of the GBR (roughly $17^{\circ}$ and $19^{\circ} \mathrm{S}$, respectively). Only three small-scale studies were undertaken on the southern $40 \%$ of the GBR to the south of Townsville, all of them on a single reef, Heron Island $\left(23^{\circ} \mathrm{S}\right)$. Three additional studies were conducted south of the GBR (see Table 1), extending the small-scale data set from $14^{\circ}$ to $31^{\circ} \mathrm{S}$, compared to $10^{\circ}-23^{\circ} \mathrm{S}$ for the large-scale study. The geographic extent of the overlap between the two data sets is $\sim 1000 \mathrm{~km}$, or $9^{\circ}$ of latitude.

\section{Latitudinal patterns of recruitment}

The large- and small-scale studies both reveal a steady 20 -fold decline in total recruitment (all taxa combined) from approximately $14^{\circ} \mathrm{S}$ to the geographic limit of coral reefs, $2100 \mathrm{~km}$ to the south (Fig. 3a; adjusted $r^{2}=0.288, P<0.01$, and $0.246, P<0.001$, respectively). Recruitment by all taxa and by spawners exhibits a similar large-scale pattern, due to the numerical dominance of spawners (Fig. 3a, b). The largescale study shows a greater effect of latitude, which accounted for $29 \%$ of the variance in spawners compared to $20 \%$ in the small-scale data set. The trend, however, is not a simple north-south gradient. Ac- cording to the large-scale study, recruitment peaked in the central portion of the Great Barrier Reef in both years, and declined to the north as well as the south (Fig. 3a, b). The smaller-scale studies did not sample the northernmost portion of the Great Barrier Reef, but they confirm the southerly decline and establish that the trend extends beyond the highest latitudes of the large-scale study to the southern limits of coral reefs in the Pacific Ocean.

Recruitment by brooders also shows a north-south decline in both data sets (Fig. 3c), although the trend was not significant for the small-scale studies, with latitude explaining only $2 \%$ of the variation. In contrast, latitude accounted for a third of the variation in brooders in the large-scale study (adjusted $r^{2}=0.344$, $P<0.001$ ). Brooders did not decline as quickly to the south as spawners in either data set (compare Fig. 3b and c). Consequently, the proportion of spawners declined at higher latitudes (Fig. 4). In the middle twothirds section of the GBR $\left(\sim 12^{\circ}-20^{\circ} \mathrm{S}\right.$; Fig. 1), spawners predominated in the large-scale study, making up close to $90 \%$ of recruits. The southern and northern ends of the GBR both show a decline in numbers of spawners, with a corresponding rise in the proportion of brooders. Consequently, the proportion of spawners was highly correlated with latitude in the large-scale study (adjusted $r^{2}=0.330, P<0.001$, Fig. 4). The small-scale studies showed a much more variable and generally lower proportion of spawners than the largescale data set, but also exhibited a significant (but much weaker) trend for a greater proportion of brooders at higher latitudes (adjusted $r^{2}=0.048, P<0.05$, Fig. 4).

In summary, both data sets reveal significant regional-scale variation in the amount and composition of recruits. Less variation in recruitment was explained by latitude in the small-scale data set, i.e., "unexplained" variation within latitudes was greater, particularly for brooders where the latitudinal signal was not statistically significant. Next we use meta-analysis to explore how methodological differences among the small-scale studies contributed to this large residual variation.

\section{Meta-analysis of small-scale studies}

Here we use as many cases as possible from the published papers, i.e., multiple deployments of panels at different sites and times were treated as replicates. We found highly significant, but generally weak, correlations among all of the continuous independent variables that we examined (Table 2). Of particular interest, latitude was confounded with the year that the study began $(r=0.50, P<0.001)$, the size of panels $(r=$ $0.37, P<0.001)$, distance from shore $(r=0.37, P<$ $0.001)$, depth $(r=0.30, P<0.001)$, the month of deployment ( $r=0.21, P<0.001)$, and the duration of deployment ( $r=-0.19, P=0.003$ ). Specifically, compared to northern studies, those done in the south were 


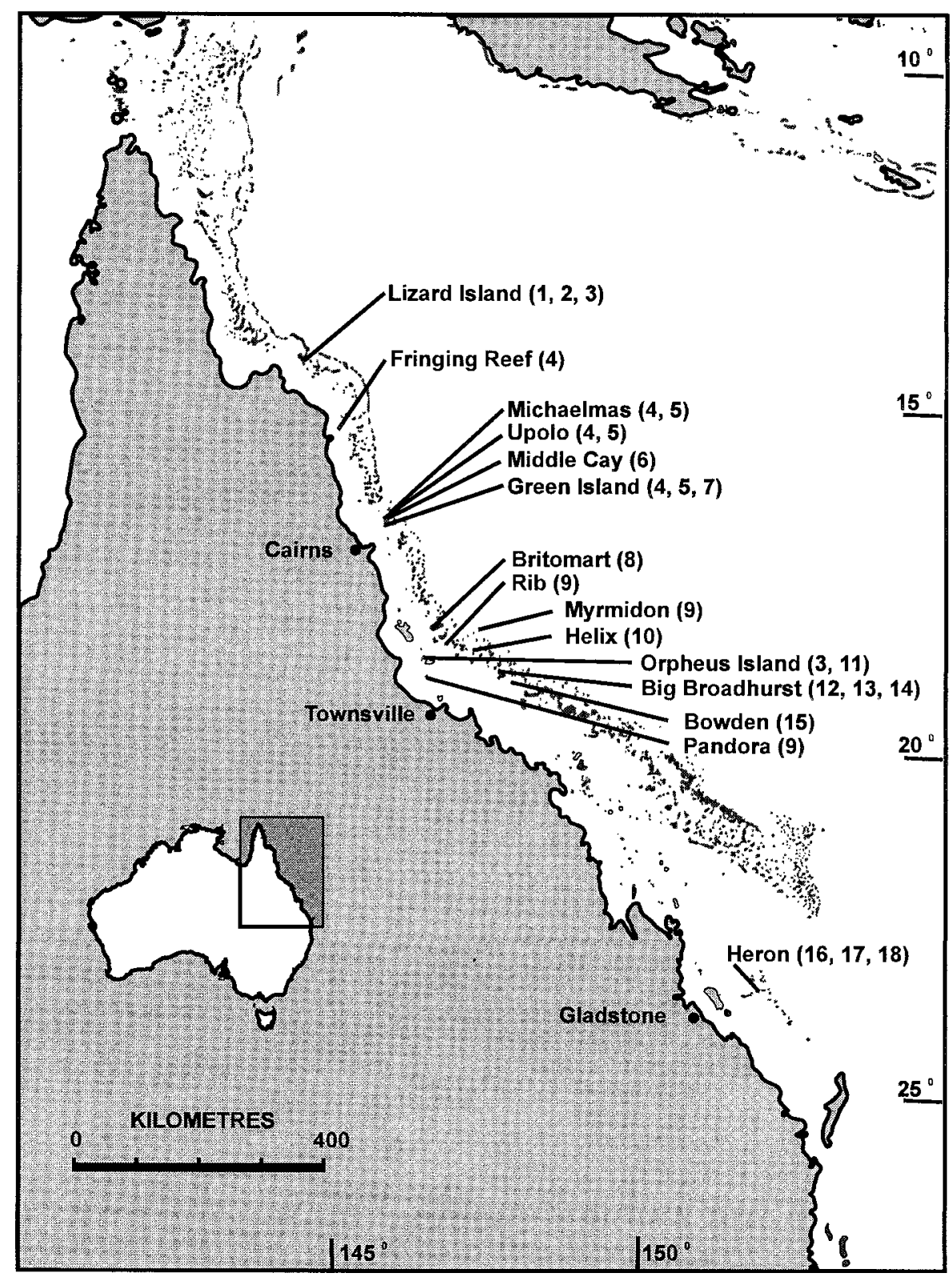

FIG. 2. Map of the Great Barrier Reef (GBR), indicating the location of reefs where recruitment of corals has been measured in 18 independent studies. A further three studies (not shown) conducted on islands to the south of the GBR at $26^{\circ}-31^{\circ} \mathrm{S}$ were also included in the meta-analysis (see Table 1 for details of the 21 studies).

generally undertaken in more recent years, using larger panels that were deployed further offshore and in deeper water, with deployments beginning later in the year and lasting on average for a shorter period. We first examined the effects of each of the 11 independent variables separately, and then entered them sequentially into multiple regression models.

In the meta-analysis, latitude on its own explained less variation than the reef-scale regressions presented earlier (Fig. 3) because of the considerable within-reef scatter in the data. Consequently, only $5.7 \%$ of the variation in total recruitment (i.e., all taxa combined,
$\left.F_{1,248}=15.02, P<0.001\right)$ and $7.3 \%$ of the variation in spawners $\left(F_{4,164}=3.22, P=0.014\right)$ was explained by latitude. Moreover, there was no effect of latitude on the density of brooders $\left(F_{4,155}=1.50, P=0.20\right)$. Therefore, a significant effect of latitude on the proportion of spawners to brooders (accounting for $11.9 \%$ of the variation, $P=0.027$ ) is attributable to a decline in spawners at southern sites rather than an increase in brooders. Recruitment was often related more strongly to individual variables other than latitude, particularly to those that measure temporal aspects of the deployment of panels. In contrast, three of the independent 


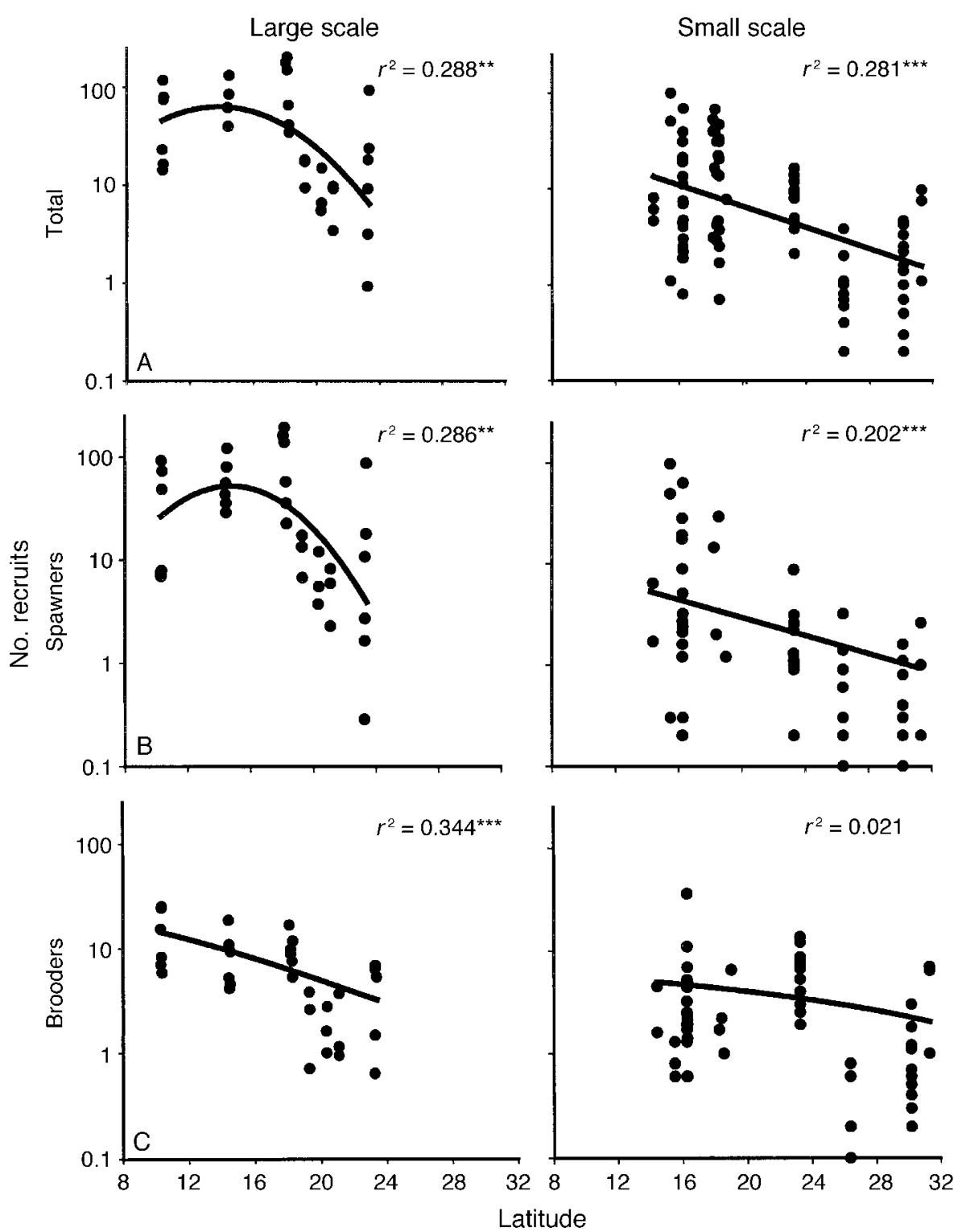

FIG. 3. Recruitment of corals vs. latitude along the east Australian coastline. Data from the large-scale study (left) and from 21 published studies (right, see Table 1). Recruitment (A) by all coral taxa; (B) by spawning corals; and (C) by brooders. Each point represents the mean number of recruits per panel on a single reef (all sites combined).

$* * P<0.01, * * * P<0.001$.

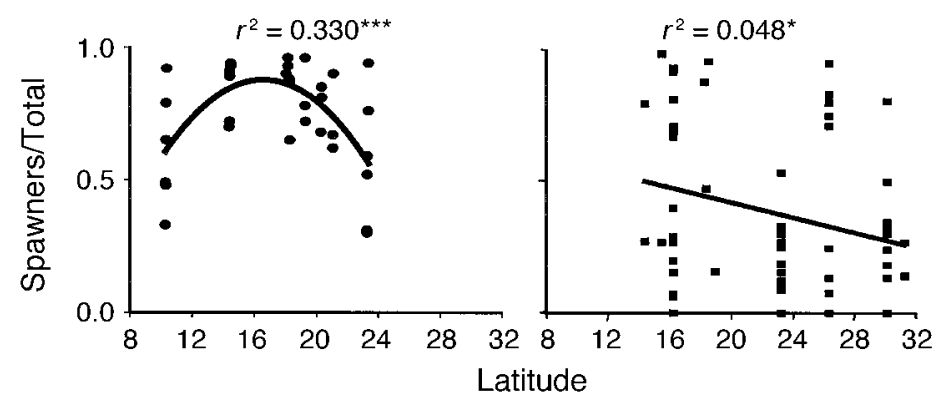

FIG. 4. The proportion of recruitment due to spawners vs. latitude, in the large-scale study (left) and in the 21 published studies (right). Zero on the $y$-axis represents $100 \%$ recruitment by brooders. $* P<0.05, * * * P<0.001$. 
TABLE 2. Pearson correlations among the continuous variables used in the meta-analysis of small-scale studies.

\begin{tabular}{|c|c|c|c|c|c|c|}
\hline Variable & Latitude & Year & Panel size & $\begin{array}{l}\text { Distance } \\
\text { from shore }\end{array}$ & Depth & $\begin{array}{l}\text { Month } \\
\text { initiated }\end{array}$ \\
\hline Year & $0.497 * * *$ & & & & & \\
\hline Panel size & $0.372 * * *$ & $0.543 * *$ & & & & \\
\hline Distance from shore & $0.372 * * *$ & 0.045 & 0.038 & & & \\
\hline Depth & $0.299 * * *$ & 0.043 & 0.036 & 0.103 & & \\
\hline Month initated & $0.205 * * *$ & 0.131 & $0.227 * *$ & 0.074 & $0.149 *$ & \\
\hline Duration & $-0.194 * *$ & -0.041 & $-0.142 *$ & -0.061 & -0.015 & -0.087 \\
\hline
\end{tabular}

Note: Based on 250 records of mean number of recruits per panel, i.e., spawners and brooders combined.

$* P<0.05, * * P<0.01$, *** $P<0.001$. Tests are two tailed.

variables we examined (the panel composition, method of deployment, and habitat) had no explanatory power for any recruitment measure (each accounting for $<2 \%$ of the variation, with $P$ values usually $>0.5$ ), and were not considered further.

Total recruitment was significantly correlated with the month and year of deployment, whether the deployment included the month of mass spawning (spawning), depth, distance from shore, duration and habitat, and latitude (Table 3a). Each of these variables on their own explained $3-10 \%$ of the variation in overall recruitment. Entering latitude first into our GAM analysis provided the best model. Once latitude was accounted for, spawning and then distance from shore explained an additional $7.4 \%$ and $10.0 \%$ of the variation, respectively (giving a total of $23.1 \%$ ). These different percentages are both higher than the variation attributable to each variable on its own, because of the correlations between them (see Table 2). No other variable added significantly to the model beyond these three. The pattern for recruitment by spawners was broadly similar, reflecting their overall numerical dominance. The same three variables were important (distance from shore, latitude, and spawning), although their sequence in the model was different (Table 4). Each one explained slightly more variation than for the total recruits model, accounting for a combined total of $29.9 \%$ of the variation in spawners. Thus, the metaanalysis confirms the latitudinal trends that were also detected by the large-scale study.

In contrast, recruitment by brooders was correlated only with distance from shore and panel size (Table 5a). Distance from shore became nonsignificant when panel size was entered first into the multiple regression model (because it had the larger $F$ value), and year became significant $\left(F_{13,154}=1.95, P=0.029\right)$. Together, panel size and year explained $18.2 \%$ of the variation in number of brooders (Table $5 \mathrm{~b}$ ). There was no effect of latitude on recruitment by brooders, either on its own $\left(F_{1,167}=1.9, P=0.11\right)$, or in combination with the other independent variables. In marked contrast, the large-scale study found a significant northsouth decline in recruitment by brooders (Fig. 3c).

Finally, variation in the ratio of brooders to spawners in the small-scale studies was explained most by the month of panel deployment, and by spawning (whether the deployment included the month of mass-spawning; Table 6). Obviously, these two are strongly correlated. Distance from the shore $(P=0.008)$, latitude $(P=$ $0.027)$, panel size $(P=0.029)$, and year $(P=0.035)$, each accounted for $11-15 \%$ of the variation. None of these variables remained significant when the month of deployment was entered first into the additive regression model. This single variable accounted for almost

TABLE 3. Generalized additive regression models (GAM) showing the percentage variation in the total number of coral recruits in the small-scale studies that is attributable (A) to individual variables and (B) to sequential combinations of variables.

\begin{tabular}{|c|c|c|c|c|c|}
\hline Variable & Type & $\mathrm{df}$ & $F$ & $P$ & Variation $(\%)$ \\
\hline \multicolumn{6}{|l|}{ A) Individual variables } \\
\hline $\begin{array}{l}\text { Month initiated } \\
\text { Year } \\
\text { Latitude } \\
\text { Spawning } \\
\text { Depth } \\
\text { Distance from shore } \\
\text { Duration } \\
\text { Habitat }\end{array}$ & $\begin{array}{l}\text { discrete } \\
\text { continuous } \\
\text { continuous } \\
\text { discrete } \\
\text { continuous } \\
\text { continuous } \\
\text { continuous } \\
\text { discrete }\end{array}$ & $\begin{array}{l}9,240 \\
4,245 \\
1,248 \\
1,248 \\
4,245 \\
4,245 \\
4,245 \\
2,247\end{array}$ & $\begin{array}{r}3.04 \\
4.65 \\
15.02 \\
13.79 \\
3.41 \\
3.13 \\
2.85 \\
4.04\end{array}$ & $\begin{array}{r}0.002 \\
0.001 \\
<0.001 \\
<0.001 \\
0.010 \\
0.016 \\
0.024 \\
0.019\end{array}$ & $\begin{array}{r}10.24 \\
7.06 \\
5.71 \\
5.33 \\
5.27 \\
4.86 \\
4.45 \\
3.17\end{array}$ \\
\hline \multicolumn{6}{|c|}{ B) Sequential combination of variables } \\
\hline $\begin{array}{l}\text { Latitude } \\
\text { Spawning } \\
\text { Distance from shore } \\
\text { Total }\end{array}$ & $\begin{array}{l}\text { continuous } \\
\text { discrete } \\
\text { continuous }\end{array}$ & $\begin{array}{l}1,248 \\
1,247 \\
4,243\end{array}$ & $\begin{array}{r}15.02 \\
21.17 \\
7.88\end{array}$ & $\begin{array}{l}<0.001 \\
<0.001 \\
<0.001\end{array}$ & $\begin{array}{r}5.71 \\
7.44 \\
9.98 \\
23.13\end{array}$ \\
\hline
\end{tabular}


TABLE 4. Regression models showing the percentage variation in the number of spawned recruits in the small-scale studies which is attributable (A) to individual independent variables, and (B) to sequential combinations of variables.

\begin{tabular}{llcrrr}
\hline \hline \multicolumn{1}{c}{ Variable } & \multicolumn{1}{c}{ Type } & df & $F$ & $P$ & Variation $(\%)$ \\
\hline A) Independent variables & & & & & \\
Month initiated & discrete & 8,160 & 3.95 & $<0.001$ & 16.48 \\
Distance from shore & continuous & 4,164 & 6.78 & $<0.001$ & 14.19 \\
Latitude & continuous & 4,164 & 3.22 & 0.014 & 7.28 \\
Year & continuous & 4,164 & 2.63 & 0.036 & 6.03 \\
Spawning & discrete & 1,167 & 8.46 & 0.004 & 4.82 \\
B) Sequential combination & of variables & & & & \\
Distance from shore & continuous & 4,164 & 6.78 & $<0.001$ & 14.19 \\
Latitude & continuous & 1,163 & 19.93 & $<0.001$ & 9.35 \\
Spawning & discrete & 1,162 & 14.75 & $<0.001$ & 6.38 \\
Total & & & & 29.92 \\
\hline
\end{tabular}

half $(47 \%)$ of the variation in the proportion of spawners in the small-scale studies.

\section{Discussion}

\section{Meta-analysis of large-scale patterns}

Meta-analysis is a developing method for quantitatively synthesizing results across studies. Recent reviews and applications have emphasized its great potential, particularly in relation to experimental data, where studies can be compared in terms of a common metric of effect size (e.g., Gurevitch and Hedges 1993, Osenberg et al. 1999). Meta-analysis also has the potential to reveal large-scale patterns in space or time from smaller-scale descriptive data (e.g., Stehli and Wells 1969, O'Connor 1985, Taylor 1987). Our study is unusual because we have the capacity to compare such a meta-analysis with a large-scale study of the same system.

The two approaches we used (large-scale sampling and meta-analysis) both have their strengths and weaknesses. One general conclusion revealed by our comparison is that "missing data" is likely to be a significant impediment to meta-analysis of regional-scale patterns. In many cases, the spatial extent and/or distribution of the small-scale studies will be unsuitable for detecting latitudinal trends, since individual studies are not designed for this purpose. For example, a strong clustering of studies near centers of research would result in regression analysis of regional gradients being heavily influenced by a handful of points from poorly studied regions. In our study, the uneven distribution of reefs in the small-scale data set (Fig. 2) undoubtedly reflects the easier access to study sites that are located close to maritime centers (Townsville and Cairns), or to two major field research stations on the GBR (on Lizard and Heron Islands at $14^{\circ}$ and $23^{\circ} \mathrm{S}$, respectively). Furthermore, the hump-shaped pattern in recruitment by all taxa and by spawners from $10^{\circ}$ to $23^{\circ}$ $\mathrm{S}$ on the GBR (Fig. 3) could not be confirmed by the meta-analysis of small-scale studies because none of them extended further north than $14^{\circ} \mathrm{S}$. Large-scale studies are more likely to have an evenly distributed spatial arrangement, and a hierarchical design and analysis will reveal small- and medium-scale variation as well as the overall, regional trend (e.g., Hughes et al. 1999, 2000). Undoubtedly, much of the unexplained variation in the small-scale studies is due to local differences from site to site within reefs, which cannot be partitioned out because the overall sampling "design" is not nested or balanced.

TABLE 5. Regression models showing the percentage variation in the number of brooded recruits in the small-scale studies which is attributable (A) to individual independent variables, and (B) to sequential combinations of variables.

\begin{tabular}{|c|c|c|c|c|c|}
\hline Variable & Type & $\mathrm{df}$ & $F$ & $P$ & Variation (\%) \\
\hline \multicolumn{6}{|l|}{ A) Independent variables } \\
\hline $\begin{array}{l}\text { Year } \\
\text { Distance from shore } \\
\text { Panel size }\end{array}$ & $\begin{array}{l}\text { discrete } \\
\text { continuous } \\
\text { continuous }\end{array}$ & $\begin{array}{r}13,155 \\
4,164 \\
4,164\end{array}$ & $\begin{array}{l}1.45 \\
3.04 \\
8.43\end{array}$ & $\begin{array}{l}0.140 \\
0.019 \\
0.004\end{array}$ & $\begin{array}{r}10.81 \\
6.91 \\
4.80\end{array}$ \\
\hline \multicolumn{6}{|c|}{ B) Sequential combination of variables } \\
\hline $\begin{array}{l}\text { Panel size } \\
\text { Year } \\
\text { Total }\end{array}$ & $\begin{array}{l}\text { continuous } \\
\text { discrete }\end{array}$ & $\begin{array}{r}1,167 \\
13,154\end{array}$ & $\begin{array}{l}8.43 \\
1.95\end{array}$ & $\begin{array}{l}0.004 \\
0.029\end{array}$ & $\begin{array}{r}4.80 \\
13.43 \\
18.23\end{array}$ \\
\hline
\end{tabular}

Note: Recruitment by brooders was not significantly correlated with latitude. Year became significant once the effects of panel size were accounted for. 
TABLE 6. Regression models showing the percentage variation in the ratio of spawners to brooders in the small-scale studies that is attributable to individual variables.

\begin{tabular}{lllrr}
\hline \hline \multicolumn{1}{c}{ Variable } & \multicolumn{1}{c}{ Type } & \multicolumn{1}{c}{$\mathrm{df}$} & $P$ & Variation $(\%)$ \\
\hline Month initiated & discrete & 8,151 & $<0.001$ & 47.02 \\
Spawning & discrete & 1,158 & $<0.001$ & 23.26 \\
Distance from shore & continuous & 4,155 & 0.008 & 15.02 \\
Latitude & continuous & 4,155 & 0.027 & 11.86 \\
Panel size & continuous & 4,155 & 0.029 & 11.75 \\
Year & continuous & 4,155 & 0.035 & 11.17 \\
\hline
\end{tabular}

Note: Once the effects of month initiated was accounted for in multiple regression models no other variable remained significant.

The choice of which studies to include in a metaanalysis often has a critical effect on the patterns that emerge (e.g., Englund et al. 1999). Selection of studies is often subjective (e.g., based on a perception of the quality of the data, the amount of replication, experience of the authors, etc.), and there is an unfortunate tendency for bias towards choosing a subset of the available information which support a preconceived outcome (Mahoney 1977). Accordingly, we chose every available study of coral recruitment from the geographic region of interest. Another source of error in meta-analyses is the tendency for authors not to publish negative results (e.g., a nonsignificant experimental outcome), the so-called "file drawer effect." This could also happen with descriptive data, e.g., if estimates of abundance that were zero or very low were not reported. We canvassed our colleagues working on recruitment of corals in Australia to rule out this possibility. It is no accident, however, that much of the literature on coral recruitment comes from the Great Barrier Reef, because rates of recruitment reported from elsewhere (e.g., in the Caribbean) are often much lower (e.g., Birkeland 1988, Richmond and Hunter 1990, Hughes et al. 1999, and references therein). Consequently, a paucity of published data from locations with very low recruitment would make a global metaanalysis problematical. In general, meta-analysis is unlikely to be fruitful where the range of the whole data set is small or where mean data values are close to zero. In our study, for example, meta-analysis detected the 20-fold latitudinal decline in the density of spawned recruits, but failed to resolve the more subtle regionalscale variation in brooders.

The inclusion of multiple years (14 separate years over a 16-yr period) in the small-scale data set potentially provides a major advantage over the large-scale study, because a longer time-scale can reveal spatial patterns that are not wholly consistent among years. Furthermore, a multi-year meta-analysis can explicitly examine longer term temporal variation. In our analysis, the year of each study had no significant effect on total recruitment, recruitment by spawners, or the ratio of brooders to spawners (Tables $3 a, 3 b, 5$ ), indicting that the regional-scale patterns are consistent over time. However, recruitment by brooders did vary significantly from year to year (Table $3 b$ ), which may account for the failure of the meta-analysis to detect a consistent regional pattern. In contrast to the metaanalysis, the large-scale study was conducted only twice, in two consecutive years, one or both of which conceivably could have been unrepresentative. However, the patterns of recruitment in both years of the large-scale study were very similar (see Hughes et al. 1999, 2000), although this may well have been sheer good luck. Generally, the cost of large-scale sampling is substantial, which makes it difficult to repeat. Metaanalysis, on the other hand, by definition involves no new field costs since multi-year data can be derived from the literature.

The main drawback of using small-scale investigations to detect regional patterns is the noise in the data due to differences in methods among published studies. In our analysis, these methodological differences (e.g., distance from shore, panel size, depth, etc.) had surprisingly modest effects (Tables 3-5), but this is unlikely to be generally true, especially where regionalscale trends are more subtle than the order of magnitude variation in recruitment that we examined. Furthermore, latitude was positively or negatively correlated with most of these variables (Table 2). This is likely to be a general (and undesirable) property of metaanalysis: a nonrandom spatial distribution of methodologies arising from different research teams in different locations. These correlations raise the possibility that any large-scale pattern detectable in small-scale studies could simply be due to regional variation in methodology rather than biology. Alternatively, regional patterns could be partially obscured by confounding methodologies. In our study, we explicitly accounted for differences in methodologies, and the concordance between the small- and large-scale data sets gives us some confidence in concluding that the latitudinal patterns in recruitment are indeed real. Moreover, we are beginning to understand some of the processes that are responsible for the regional trends (see Discussion: Mechanisms of large-scale recruitment variation).

In summary, a large-scale study has numerous advantages over meta-analysis in terms of the comparability of data from different locations or census intervals. A single regional-scale study is also more likely to be developed in conjunction with predetermined sta- 
tistical procedures, based on a uniform sampling design. The methods are invariably more homogeneous, the results are always expressed as the same metric, and the involvement of fewer people with similar training means that there is less likelihood of bias between observers or between research groups. Most importantly, the data are likely to be less noisy, unencumbered by extraneous methodological factors which often differ among individual small-scale studies. Of course, the downside is the expense, time, and effort associated with a larger sampling regime compared to an analysis of previously published studies (although we strongly suspect that our single-regional study of recruitment by corals was cheaper than the combined cost of the 21 individual field studies). Furthermore, sampling or experiments conducted at larger spatial scales are more difficult to repeat, and the limited temporal window could be unrepresentative.

\section{Mechanisms of large-scale recruitment variation}

The results from meta-analysis are particularly useful because they can be used to generate hypotheses addressing the mechanisms underlying large-scale patterns. The meta-analysis presented here demonstrates that the timing of deployment of panels had a critical impact on the amount and species composition of recruits. Intuitively, we would expect low rates of recruitment when and where few larvae are produced. Conversely, higher recruitment should result in time periods (seasons or years) or regions that have higher rates of production of larvae. Elsewhere, (as a component of the large-scale study) we tested the hypothesis that variation in recruitment by spawning acroporids (Fig. 3) was related to temporal and regional variation in their fecundity. We found large differences among reefs in the proportion of adult corals that underwent mass spawning in each of two years of the study, which accounted for a huge proportion (72\%) of the variation in their recruitment among the 33 reefs that we sampled (Hughes et al. 2000). Moreover, once regional variation in the intensity of spawning was accounted for statistically, there was no further effect of latitude on large-scale patterns of recruitment by spawning corals. Consequently, we suggest that latitudinal patterns of recruitment on the GBR (Figs. 3 and 4) are driven by regional-scale gradients in the number of larvae produced each season, with reefs and sectors in the central GBR having higher recruitment by spawning corals (Fig. 3) because this region produces more larvae than elsewhere. Similarly, the continued decline in recruitment south of the GBR is probably due to a dwindling larval pool, as populations of breeding adults become smaller and more isolated.

The mechanisms of recruitment could also account for some of the disparities between the large- and small-scale studies. Specifically, the large-scale study had a higher density of recruits, and a greater proportion of spawners (Figs. 3 and 4), almost certainly be- cause of differences in the timing and duration of the panel deployments in the two data sets. The large-scale deployments in late 1995 and 1996 were initiated 9$11 \mathrm{~d}$ before the predicted annual mass spawning of corals in November/December. This narrow timing was designed to allow the development of chemical or physical cues from bacteria or algae on the panels, which facilitate the settlement and metamorphosis of many corals (e.g., Morse et al. 1994). The annual peak settlement of spawning corals would have occurred 3-7 $\mathrm{d}$ after the release of gametes, $\sim 2$ wk after the panels were placed in position. In contrast, half of the smallscale studies missed entirely the annual mass spawning event, which obviously reduced the abundance of spawners and increased the proportion of brooders (that are released over a more protracted [lunar] breeding cycle, see Harrison and Wallace 1990, Tanner 1996). In addition, 20 of the 21 small-scale studies had longer durations than the large-scale data set (Table 1). Longer submergence times are likely to favor the accumulation of multiple cohorts of brooders, while a single annual cohort of spawners should rapidly decline due to mortality (Dunstan and Johnson 1998, Baird and Hughes 2000). Note, however, that the latitudinal decline in recruitment and the relative increase in brooders to the south cannot be explained by variation in the timing or duration of panel deployments among the smallscale studies. The southernmost studies were conducted closer to spawning (later in the year) and they were shorter (i.e., latitude was positively correlated with the month of initiation, and negatively correlated with duration, see Table 2). This should have produced an increase in numbers and proportion of spawners, the opposite of the pattern detected in both the large- and small-scale analyses. Thus, the large-scale pattern is not an artifact of methodology.

Large-scale hydrodynamics does not appear to play a major role in determining regional patterns of recruitment by corals along the Great Barrier Reef. Although the peak recruitment by spawners at $14^{\circ}-18^{\circ} \mathrm{S}$ coincides with the predominant westward-flowing current which flows from the Coral Sea to the outer Great Barrier Reef, it is unlikely that substantial transport of coral larvae occurs at this scale, for several reasons. First, the area of reefs (a proxy for reproductive output) declines precipitously eastwards from the GBR. Consequently, the production of larvae by isolated oceanic reefs is unlikely to be a significant input onto the vast expanse of the Great Barrier Reef. Second, the GBR is much more speciose than reefs to the east, having $\sim 100$ more species than on New Caledonia, the nearest large reef system, $1100 \mathrm{~km}$ to the east (see Veron 1993). This biogeographic distinction implies that the Coral Sea is a significant barrier to dispersal, at least from west to east. Clearly, for the species found only on the GBR (and further north), the Coral Sea cannot be a source of larvae. Third, the strong concordance between sector-scale patterns of spawning and recruit- 
ment by corals on the Great Barrier Reef suggests that dispersal by most species is limited, and that areas with high fecundity do not act as a source for downstream reefs that have lower reproductive outputs (Hughes et al. 2000). Fourth, recent estimates of the genetic variability of nine species of corals along the length of the Great Barrier Reef indicate that most successful recruitment is localized (Ayre and Hughes 2000). Accordingly, the very substantial latitudinal decline in larval recruitment we recorded (Fig. 3) occurs despite the potential for southerly transport by the East Australia Current, which implies that significant regionalscale transport of corals is prevented by early settlement (on natal or neighboring reefs), local entrapment of larvae due to reef-scale hydrodynamics (e.g., Black et al. 1991), and by the depletion of larval cohorts caused by mortality in the plankton.

In conclusion, our results show that that the dynamics of coral reefs vary substantially at regional scales. The latitudinal changes in the rate and composition of recruitment that we documented undoubtedly contribute to broad-scale biogeographic shifts in the community structure and diversity of coral assemblages. Similar regional-scale pattern in recruitment may occur on Pacific coral reefs in the northern hemisphere, where diversity and adult coral abundances decline from south to north along the length of the Ryukyu Island chain $\left(24^{\circ}-32^{\circ} \mathrm{N}\right)$. High diversity reefs to the south are dominated by spawners (Hayashibara et al. 1993, Morse et al. 1996), compared to depauperate northern locations that have lower rates of recruitment, mainly by brooders (S. Nojima, personal comment). Similar regionalscale patterns in recruitment are becoming apparent in other intertidal and subtidal marine systems (e.g., along the western coast of North America; see Connolly and Roughgarden 1998, 1999, Ebert and Russell 1988). As demonstrated here, meta-analysis provides a powerful approach for elucidating large-scale phenomena such as these, and for generating testable hypotheses about their causes and consequences.

\section{ACKNOWLEDGMENTS}

We are very grateful to the authors listed in Table 1, whose published data allowed us to undertake the meta-analysis, and to 51 graduate student volunteers from James Cook University who provided crucial assistance with the large-scale fieldwork in 1995-1997. We thank D. Ayre, J. Caley, H. Choat, and P. Doherty for comments on the manuscript. Research was funded by grants to T. Hughes from the Australian Research Council. This is contribution No. 183 of the Coral Ecology Group at James Cook University.

\section{Literature Cited}

Arnqvist, G., and D. Wooster. 1995. Meta-analysis: synthesizing research findings in ecology and evolution. Trends in Ecology and Evolution 10:236-240.

Ayre, D. J., and T. P. Hughes. 2000. Genotypic diversity and gene flow in brooding and spawning corals along the Great Barrier Reef, Australia. Evolution 54:1590-1605.

Babcock, R. C. 1988. Fine-scale spatial and temporal patterns in coral settlement. Pages 635-639 in J. H. Choat, et al., editors. Proceedings of the Sixth International Coral Reef Symposium, Townsville, Australia. Volume 2.

Babcock, R. C., G. D. Bull, P. L. Harrison, A. J. Heyward, J. K. Oliver, C. C. Wallace, and B. L. Willis. 1986. Synchronous spawnings of 105 scleractinian coral species on the Great Barrier Reef. Marine Biology 90:379-394.

Baird, A. H., and T. P. Hughes. 1997. Spatial variation in coral recruitment around Lizard Island, Australia. Pages 1207-1211 in H. Lessios and I. G. Macintyre, editors. Proceedings of the Eighth International Coral Reef Symposium, Panama. Smithsonian Tropical Research Institute, Balboa, Republic of Panama.

Baird, A. H., and T. P. Hughes. 2000. Competitive dominance by tabular corals: an experimental analysis. Journal of Experimental Marine Biology and Ecology 251:117-132.

Banks, S. A., and V. J. Harriott. 1996. Patterns of coral recruitment at the Gneering Shoals, southeast Queensland, Australia. Coral Reefs 15:225-230.

Birkeland, C. 1988. Geographic comparisons of coral-reef community process. Pages 211-220 in J. H. Choat, et al., editors. Proceedings of the Sixth International Coral Reef Symposium, Townsville, Australia. Volume 2.

Black, K. P., P. J. Moran, and L. S. Hammond. 1991. Numerical models show coral reefs can be self-seeding. Marine Ecology Progress Series 74:1-11.

Bothwell, A. M. 1981. Fragmentation, a means of asexual reproduction and dispersal in the coral genus Acropora (Scleractinia: Astrocoeniidae: Acroporidae)-a preliminary report. Pages 137-144 in E. D. Gomez, C. E. Birkeland, R. W. Buddemeier, R. E. Johannes, J. A. Marsh, Jr., and R. T. Tsuda, editors. Proceedings of the Fourth International Coral Reef Symposium, Manila. Marine Sciences Center, University of the Philippines, Quezon City, Philippines.

Caley, M. J., M. H. Carr, M. A. Hixon, T. P. Hughes, G. P. Jones, and B. A. Menge. 1996. Recruitment and the local dynamics of open marine populations. Annual Reviews of Ecology and Systematics 27:477-498.

Carpenter, S. R. 1990. Large-scale perturbations: opportunities for innovation. Ecology 70:1142-1152.

Connell, J. H., T. P. Hughes, and C. C. Wallace. 1997. A 30yr study of coral abundance, recruitment, and disturbance at several scales in space and time. Ecological Monographs 67:461-488.

Connolly, S. R., and J. Roughgarden. 1998. A latitudinal gradient in intertidal community structure: evidence for an oceanographically-based synthesis of marine community theory. American Naturalist 151:311-326.

Connolly, S. R., and J. Roughgarden. 1999. Theory of marine communities: competition, predation, and recruitment-dependent interaction strength. Ecological Monographs 69: 277-296.

Crossland, C. 1988. Latitudinal comparisons of coral reef structure and function. Pages 221-266 in J. H. Choat, et al., editors. Proceedings of the Sixth International Coral Reef Symposium, Townsville, Australia. Volume 2.

Dayton, P. K., and M. J. Tegner. 1984. The importance of scale in community ecology. Pages $457-481$ in P. W. Price, C. N. Slobodchikoff, and W. S. Gaud, editors. A new ecology. John Wiley and Sons, London, UK.

Downing, J. A., C. W. Osenberg, and O. Sarnelle. 1999. Meta-analysis of marine nutrient-enrichment experiments: variation in the magnitude of nutrient limitation. Ecology 80:1157-1167.

Dunstan, P. K., and C. R. Johnson. 1998. Spatio-temporal variation in coral recruitment at different scales on Heron Reef, southern Great Barrier Reef. Coral Reefs 17:71-81. Eberhardt, L. L., and J. M. Thomas. 1991. Designing environmental field studies. Ecological Monographs 61:53-73. Ebert, T. A., and M. P. Russell. 1988. Latitudinal variation 
in size structure of the west coast purple sea urchin: a correlation with headlands. Limnology and Oceanography 33:286-354

Edwards, P. J., R. M. May, and N. R. Webb, editors. 1994. Large-scale ecology and conservation biology. Blackwell Science, Oxford, UK.

Englund, G., O. Sarnelle, and S. D. Cooper. 1999. The importance of data-selection criteria: meta-analysis of stream predation experiments. Ecology 80:1132-1142.

Fisk, D. A., and V. J. Harriott. 1990. Spatial and temporal variation in coral recruitment on the Great Barrier Reef: implications for dispersal hypotheses. Marine Biology 107: 485-490.

Fisk, D., and V. J. Harriott. 1993. Are understorey corals recruitment limited? Pages 513-516 in Proceedings of the Seventh International Coral Reef Symposium. Volume 1. University of Guam Press, Mangilao, Guam.

Gaines, S. D., and J. Roughgarden. 1985. Larval settlement rates: a leading determinant of structure in an ecological community of the marine intertidal zone. Proceedings of the National Academy of Science, USA 82:3707-3701.

Glass, G. V., B. McGraw, and M. L. Smith. 1981. Metaanalysis in social research. Sage Publications, Beverly Hills, California, USA.

Goldberg, D. E., T. Rajaneimi, J. Gurevitch, and A. StewartOaten. 1999. Empirical approaches to quantifying interaction intensity: competition and facilitation along productivity gradients. Ecology 80:1118-1132.

Gurevitch, J., and L. V. Hedges. 1993. Meta-analysis: combining the results of independent experiments. Pages 378398 in S. M. Scheiner and J. Gurevitch, editors. Design and analysis of ecological experiments. Chapman and Hall, New York, New York, USA.

Harriott, V. J. 1985. Recruitment patterns of scleractinian corals at Lizard Island, Great Barrier Reef. Pages 367-372 in C. Gabrie and M. Harmelin Vivien, editors. Proceedings of the Fifth International Coral Reef Congress, Tahiti. Antenne Museum-Ephe, Moorea, French Polynesia.

Harriott, V. J. 1992. Recruitment patterns of scleractinian corals in an isolated sub-tropical reef system. Coral Reefs 11:215-219.

Harriott, V. J., and S. A. Banks. 1995. Recruitment of scleractinian corals in the Solitary Islands Marine Reserve, a high latitude coral-dominated community in eastern Australia. Marine Ecology Progress Series 123:155-161.

Harriott, V. J., and D. A. Fisk. 1987. A comparison of settlement plate types for experiments on the recruitment of scleractinian corals. Marine Ecology Progress Series 37: 201-208.

Harriott, V. J., and D. A. Fisk. 1988. Recruitment patterns of scleractinian corals: a study of three reefs. Australian Journal of Marine and Freshwater Research 39:409-416.

Harriott, V. J., P. L. Harrison, and S. A. Banks. 1995. The coral comunities of Lord Howe Island. Australian Journal of Marine and Freshwater Research 46:457-465.

Harriott, V. J., and C. J. Simpson. 1996. Coral recruitment on tropical and subtropical reefs in Western Australia. Pages 1191-1196 in H. Lessios and I. G. Macintyre, editors. Proceedings of the Eighth International Coral Reef Symposium, Panama. Volume 2. Smithsonian Tropical Research Institute, Balboa, Republic of Panama.

Harrison, P. L., R. C. Babcock, G. D. Bull, J. K. Oliver, C. C. Wallace, and B. L. Willis. 1984. Mass-spawning in tropical reef corals. Science 223:1186-1189.

Harrison, P. L., and C. C. Wallace. 1990. Reproduction, dispersal and recruitment of scleractinian corals. Pages 133207 in Z. Dubinsky, editor. Ecosystems of the world. Volume 25. Elsevier, New York, New York, USA.

Hastie, T. J., and R. Tibshirani. 1990. Generalized additive models. Chapman and Hall, London, UK.
Hayashibara, T., K. Shimoike, T. Kimura, S. Hosaka, A. Heyward, P. Harrison, K. Kudo, and M. Omori. 1993. Patterns of coral spawning at Akajima Island, Okinawa, Japan. Marine Ecology Progress Series 101:253-262.

Hedges, L. V., and I. Olkin. 1985. Statistical methods for meta-analysis. Academic Press, New York, New York, USA.

Hughes, T. P. 1990. Recruitment limitation, mortality and population regulation in a sessile invertebrate, Cellepora pumicosa (Bryozoa, Anasca). Ecology 71:12-20.

Hughes, T. P., A. H. Baird, E. A. Dinsdale, N. A. Molchaniwskyj, M. S. Pratchett, J. E. Tanner, and B. L. Willis. 1999. Patterns of recruitment and abundance of corals along the Great Barrier Reef. Nature 397:59-63.

Hughes, T. P., A. H. Baird, E. A. Dinsdale, N. A. Molchaniwskyj, M. S. Pratchett, J. E. Tanner, and B. L. Willis. 2000. Supply-side ecology works both ways: the link between benthic adults, fecundity, and larval recruits. Ecology 81: 2241-2249.

Hughes, T. P., and J. E. Tanner. 2000. Recruitment failure, life histories, and long-term decline of Caribbean corals. Ecology 81:2250-2263.

Karlson, R. H., and D. R. Levitan. 1990. Recruitment limitation in open populations of Diadema antillarum: an evaluation. Oecologia 82:40-44.

Mahoney, M. J. 1977. Publication prejudices: an experimental study of confirmatory bias in the peer review systems. Cognitive Therapy and Research 1:161-175.

Maida, M., P. W. Sammarco, and J. C. Coll. 1995a. Effects of soft corals on scleractinian coral recruitment. 1: directional allelopathy and inhibition of settlement. Marine Ecology Progress Series 121:191-202.

Maida, M., P. W. Sammarco, and J. C. Coll. 1995b. Preliminary evidence for directional allelopathic effects of the soft coral Sinularia flexibilis (Alcyonacea: Octocorallia) on scleractinian coral recruitment. Bulletin of Marine Science 56:303-311.

Menge, B. A., B. A. Daley, J. Lubchenko, E. Sanford, E. Dahlhoff, P. M. Halpin, G. Hudson, and J. L. Burnaford. 1999. Top-down and bottom-up regulation of New Zealand rocky intertidal communities. Ecological Monographs 69: 297-330.

Milicich, M. J. 1994. Dynamic coupling of reef fish replenishment and oceanographic processes. Marine Ecology Progress Series 110:135-144.

Morse, A. N. C., K. Iwao, M. Baba, K. Shiroike, T. Hayashibara, and M. Omori. 1994. An ancient chemosensory mechanism brings new life to coral reefs. Biological Bulletin 191: 149-154.

Mundy, C. N. 2000. An appraisal of methods used in coral recruitment studies. Coral Reefs 19:124-131.

O'Connor, R. J. 1985. Long-term monitoring of British bird populations. Ornis Fennica 62:73-79.

Osenberg, C. W., O. Sarnelle, S. D. Cooper, and R. D. Holt. 1999. Resolving ecological questions through meta-analysis: goals, metrics, and models. Ecology 80:1105-1117.

Rastetter, E. B., A. W. King, B. J. Cosby, G. M. Hornberger, R. V. O'Neill, and J. E. Hobbie. 1992. Aggregating fine scale ecological knowledge to model coarse-scale attributes of ecosystems. Ecological Applications 2:55-70.

Richmond, R. H. 1987. Energetics, competency and longdistance dispersal of planula larvae of the coral Pocillopora damicornis. Marine Biology 93:527-533.

Richmond, R. H., and C. L. Hunter. 1990. Reproduction and recruitment of corals: comparisons among the Caribbean, the tropical Pacific, and the Red Sea. Marine Ecology Progress Series 60:185-203.

Rosenzweig, M. L. 1995. Species diversity in space and time. Cambridge University Press, Cambridge, UK.

Sachs, H. S., J. Berrier, D. Reitman, V. A. Ancona-Berk, and 
T. C. Chalmer. 1987. Meta-analysis of randomized controlled trials. New England Journal of Medicine 316:450455.

Sammarco, P. W. 1991. Geographically specific recruitment and post settlement mortality as influences on coral communities: the cross continental shelf transplant experiments. Limnology and Oceanography. 36:496-514.

Sammarco, P. W., and J. C. Andrews. 1988. Localized dispersal and recruitment patterns in Great Barrier Reef corals. Limnology and Oceanography 34:896-912.

Sammarco, P. W., and J. H. Carleton. 1981. Damselfish territoriality and coral community structure: reduced grazing, coral recruitment, and effects on coral spat. Pages 525-535 in E. D. Gomez, C. E. Birkeland, R. W. Buddemeier, R. E. Johannes, J. A. Marsh, Jr., and R. T. Tsuda, editors. Proceedings of the Fourth International Coral Reef Symposium, Manila. Marine Sciences Center, University of the Philippines, Quezon City, Philippines.

Schneider, D. C. 1994. Quantitative ecology: spatial and temporal scaling. Academic Press, San Diego, California, USA.

Schneider, D. C., R. Walters, S. Thrush, and P. Dayton. 1997. Scale-up of ecological experiments: density variation in the mobile bivalve Macomona liliana. Journal of Experimental Marine Biology and Ecology 216:129-152.

Stehli, F. G., and J. W. Wells. 1969. Diversity and age patterns in hermatypic corals. Systematic Zoology 20:115-126.

Tanner, J. E. 1996. Seasonal and lunar periodicity in the reproduction of pocilloporid corals. Coral Reefs 15:59-66.

Taylor, L. R. 1987. Objective and experiment in long-term research. Pages 20-70 in G. E. Likens, editor. Long-term studies in ecology: approaches and alternatives. SpringerVerlag, New York, New York, USA.
Thrush, S. F., et al. 1997. Scaling-up from experiments to complex ecological systems: Where to next? Journal of Experimental Marine Biology and Ecology 216:243-254.

Veron, J. E. N. 1993. A biogeographic database of hermatypic corals. Australian Institute of Marine Science Monograph Series. Volume 10. University of Hawaii Press, Honolulu. Veron, J. E. N., and T. J. Done. 1979. Corals and coral communities of Lord Howe Island. Australian Journal of Marine and Freshwater Research 30:203-236.

Wallace, C. C. $1985 a$. Seasonal peaks and annual fluctuations in recruitment of juvenile scleractinian corals. Marine Ecology Progress Series 21:289-298.

Wallace, C. C. $1985 b$. Reproduction, recruitment and fragmentation in nine sympatric species of the coral genus Acropora. Marine Biology 88:217-233.

Wallace, C. C., and G. D. Bull. 1981. Patterns of juvenile coral recruitment on a reef front during a spring-summer spawning period. Pages 345-350 in E. D. Gomez, C. E. Birkeland, R. W. Buddemeier, R. E. Johannes, J. A. Marsh, Jr., and R. T. Tsuda, editors. Proceedings of the Fourth international coral reef symposium, Manila. Volume 2. Marine Sciences Center, University of the Philippines, Quezon City, Philippines.

Wiens, J. A. 1989. Spatial scaling in ecology. Functional Ecology 3:385-397.

Wiens, J. A., N. C. Stenseth, B. Van Horne, and R. A. Ims. 1993. Ecological mechanisms and landscape ecology. Oikos 66:369-380.

Wilson, J. R., and P. L. Harrison. 1998. Settlement-competency periods of larvae of three species of scleractinian corals. Marine Biology 131:339-345.

Wolanski, E. 1994. Physical oceanographic processes of the Great Barrier Reef. CRC Press, Boca Raton, Florida, USA. 